\title{
Nondimensional Wind and Temperature Profiles in the Atmospheric Surface Layer over the Hinterland of the Taklimakan Desert in China
}

\author{
Yongqiang Liu, ${ }^{1,2}$ Ali Mamtimin, ${ }^{3,4}$ Wen Huo, ${ }^{3,4}$ Xinghua Yang, ${ }^{3,4}$ Xinchun Liu, ${ }^{3,4}$ \\ Fan Yang, ${ }^{3,4}$ and Qing $\mathrm{He}^{3,4}$ \\ ${ }^{1}$ College of Resource \& Environmental Sciences, Xinjiang University, Urumqi 830046, China \\ ${ }^{2}$ Key Laboratory of Oasis Ecology, Ministry of Education, Urumqi 830046, China \\ ${ }^{3}$ Institute of Desert Meteorology, China Meteorological Administration, Urumqi 830002, China \\ ${ }^{4}$ Taklimakan Desert Atmospheric Environment Observation Experiment Station, Tazhong 841000, China
}

Correspondence should be addressed to Qing He; qinghe@idm.cn

Received 26 June 2015; Revised 1 October 2015; Accepted 20 October 2015

Academic Editor: Enrico Ferrero

Copyright (C) 2016 Yongqiang Liu et al. This is an open access article distributed under the Creative Commons Attribution License, which permits unrestricted use, distribution, and reproduction in any medium, provided the original work is properly cited.

Observed turbulent fluxes, wind, and temperature profiles at Tazhong station over the hinterland of the Taklimakan Desert in China have been analyzed to evaluate empirical parameters used in the profile functions of desert surface layer. The von Kármán constant derived from our observations is about 0.396 in near-neutral stratification, which is in good agreement with many other studies for different underlying surface. In our analysis, the turbulent Prandtl number is about 0.75 in near-neutral conditions. For unstable range, the nondimensional wind and temperature profile functions are best fitted by the exponents of $-1 / 4$ and $-1 / 2$, respectively. The linear relations still hold for stable stratification in this extremely arid desert. However, the parameters used in their profile functions need to be revised to be applicable for desert surfaces.

\section{Introduction}

The Monin-Obukhov similarity (MOS) theory is the landmark in modern micrometeorology for modeling atmospheric surface layer [1]. In most of the land-surface models, the surface momentum and heat flux are calculated using the wind and temperature profiles relationship based on MOS theory [2]. Since its development in the 1950s [3], the MOS theory has been widely applied in modeling atmospheric surface layer processes. However, it is limited to the surface layer above the roughness sublayer, to a range of the stability parameter $|z / L|<1$ or $|z / L|<2$, and over homogeneous surfaces [1]. Significant research has been conducted in the last several decades to improve the parameters of formulas used in MOS. For instance, Brutsaert and Kustas [4, 5] analyze the profile of mean wind velocity, of temperature, and of specific humidity under different stability conditions over macrorough terrain; some parameters of MOS were determined. Sugita and Brutsaert [6] yielded the roughness length and displacement height of the prairie in eastern Kansas by analyzing the neutral profiles of wind velocity based on MOS. Parlange and Brutsaert [7] gave new stability correction functions for wind in the unstable atmospheric boundary layer. Dias and Brutsaert [8] investigated the similarity functions for temperature and humidity; their results confirmed that, under validity of the MOS assumptions, two similarity functions are equal under stable condition. Cheng and Brutsaert [9] analyzed wind and temperature profiles based on MOS in the stable boundary layer; they proposed stability functions under weakly stable conditions. However, in this study, our focus is on evaluating and improving the parameters used for desert surface.

From MOS theory, the nondimensional wind shear and potential temperature gradient in a horizontally homogeneous surface layer are usually expressed as universal functions:

$$
\left(\frac{k z}{u_{*}}\right) \frac{\partial \bar{u}}{\partial z}=\varphi_{m}\left(\frac{z}{L}\right)
$$


TABLE 1: Coefficients in six typical forms of nondimensional profile functions ${ }^{\mathrm{a}}$.

\begin{tabular}{lcccccccc}
\hline Profile form & $\beta_{m}$ & $\gamma_{m}$ & $\beta_{h}$ & $\gamma_{h}$ & Stable & $\operatorname{Pr}_{t}$ & Unstable & $k$ \\
\hline B71 & 4.7 & 15.0 & 6.4 & 9.0 & 0.74 & 0.74 & 0.35 & Underlying surface \\
D74 & 5.0 & 16.0 & 5.0 & 16.0 & 1.0 & 1.0 & 0.41 & Wheat stubble \\
W80 & 6.9 & 22.0 & 9.2 & 13.0 & 1.0 & 1.0 & 0.41 & Ploughed field, dead grass \\
Z93 & 5.0 & 28.0 & 5.0 & 20.0 & 1.0 & 1.0 & 0.39 & Wheat stubble \\
H96 & 5.3 & 19.0 & 8.0 & 11.6 & 1.0 & 0.95 & 0.40 & Gobi Desert \\
Z03 & 4.2 & 14.6 & 4.8 & 10.0 & 0.83 & 0.73 & 0.40 & Vegetated land \\
\hline
\end{tabular}

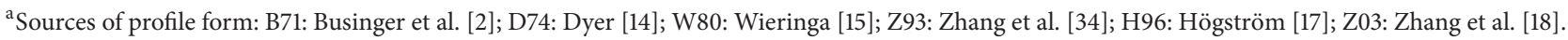

$$
\left(\frac{k z}{\theta_{*}}\right) \frac{\partial \bar{\theta}}{\partial z}=\varphi_{h}\left(\frac{z}{L}\right),
$$

where $u_{*}\left(\mathrm{~m} \mathrm{~s}^{-1}\right), \bar{u}\left(\mathrm{~m} \mathrm{~s}^{-1}\right), \theta_{*}(\mathrm{~K})$, and $\bar{\theta}(\mathrm{K})$ are observed frictional velocity, mean horizontal wind speed, temperature scale, and mean potential temperature at the height $z(\mathrm{~m})$ above the zero-plane displacement, respectively. $k$ is the von Kármán constant, $z / L$ is stability parameter (negative means unstable; positive means stable), and $L \equiv T_{0} u_{*}^{2} /\left(k g \theta_{*}\right)(\mathrm{m})$ is the Obukhov length. Here, $T_{0}(\mathrm{~K})$ is a representative temperature in the surface layer, and $g\left(\mathrm{~m} \mathrm{~s}^{-2}\right)$ is the acceleration of gravity. $\varphi_{m}$ and $\varphi_{h}$ are profile functions corresponding to momentum and heat dependent on stability $z / L$, respectively. Högström [10] suggested a revised formula with a turbulent Prandtl number $\left(\mathrm{Pr}_{t}\right)$ for temperature as

$$
\left(\frac{k}{\operatorname{Pr}_{t}}\right)\left(\frac{z}{\theta_{*}}\right) \frac{\partial \bar{\theta}}{\partial z}=\varphi_{h}\left(\frac{z}{L}\right) .
$$

In all of them, the profile functions $\varphi_{m}$ and $\varphi_{h}$ must be determined by field experiments. The semiempirical profile functions were first found by Businger et al. [2] based on the data collected from Kansas wheat-farming land. Since then, many studies [e.g., [9-18]] have derived many profile functions. Among them, the widely accepted forms are

$$
\begin{gathered}
\varphi_{m}\left(\frac{z}{L}\right)= \begin{cases}1+\frac{\beta_{m} z}{L} & \frac{z}{L}>0 \\
\left(1-\frac{\gamma_{m} z}{L}\right)^{-1 / 4} & \frac{z}{L} \leq 0,\end{cases} \\
\varphi_{h}\left(\frac{z}{L}\right)= \begin{cases}\operatorname{Pr}_{t}\left(1+\frac{\beta_{h} z}{L}\right) & \frac{z}{L}>0 \\
\operatorname{Pr}_{t}\left(1-\frac{\gamma_{h} z}{L}\right)^{-1 / 2} & \frac{z}{L} \leq 0,\end{cases}
\end{gathered}
$$

where $\beta_{m}, \gamma_{m}, \beta_{h}, \gamma_{h}$, and $\operatorname{Pr}_{t}$ are coefficients. Coefficient $\mathrm{Pr}_{t}$, describing the difference between the eddy diffusivities of momentum $K_{m}$ and of heat $K_{h}$, that is, $\operatorname{Pr}_{t}=K_{m} / K_{h}$, may be different for stable and unstable stratifications. Coefficients in six typical profile functions for different underlying surfaces are shown in Table 1. At present, profile function in Businger et al. [2] or Högström [17] is regarded as universal profile function and widely used. But it is unknown if the universal profile function remains valid in an arid and sandy surface like the Taklimakan Desert. Thus, the present study, based on both the observed fluxes and gradient wind and temperature data, attempts to evaluate and improve the functional relationships between nondimensional wind and temperature profile functions and the stability parameters over the hinterland of the Taklimakan Desert in China.

\section{Site and Observed Data}

2.1. Site. The Taklimakan Desert Atmosphere \& Environment Observation Experiment Station is located at Tazhong (hereafter Tazhong station, Figure 1). It is designed to gain knowledge of characteristics of atmospheric physics and chemistry, energy exchange of land-atmosphere interactions in a desert area. Currently, it is the only field site in the hinterland of a shifting desert and far away from cities around the Tarim Basin, the nearest distance between Tazhong and the desert edge is $220 \mathrm{~km}$. The unique environment provides good conditions for studying the atmospheric boundary layer in a desert. The Tazhong observation system comprises two stations, a main station $\left(38^{\circ} 58^{\prime} 05^{\prime \prime} \mathrm{N}, 83^{\circ} 39^{\prime} 35^{\prime \prime} \mathrm{E}, 1093 \mathrm{~m}\right)$ and a complementary station $\left(38^{\circ} 58^{\prime} 51^{\prime \prime} \mathrm{N}, 83^{\circ} 38^{\prime} 28^{\prime \prime} \mathrm{E}\right.$, $1103 \mathrm{~m}$ ). The main station is located close to the oil field area and includes an $80 \mathrm{~m}$ tower for gradient detection, a three-layer eddy-covariance (EC) system, and a radiation observation system. The complementary station is located at northwest $2.2 \mathrm{~km}$ to the main station with an EC system, sensors for radiation and soil heat flux, and an automatic weather station (AWS). The complementary station lies in an open environment, with a relatively flat underlying surface in a shifting sand area. There are a range of sand dunes surrounding the complementary station, including $850 \mathrm{~m}$ to the east, $1600 \mathrm{~m}$ to the south, and $1700 \mathrm{~m}$ to the west. The complementary station is our study site in this study.

2.2. Instrumentation. The instrumentation at our study site mainly includes an EC measurement system, a radiation observation system, and an AWS (Figure 2). The EC system has a $3 \mathrm{D}$ sonic anemometer (CSAT3, Campbell Scientific Inc., USA), which measures three-dimensional velocity and sonic virtual temperature. The installation height of the EC system is $3 \mathrm{~m}$ above the ground, and the raw data were continuously collected at a $10 \mathrm{~Hz}$ sampling frequency using a CR5000 data logger (Campbell Scientific Inc., USA). The radiation observation system includes four separate components (CNR-1, 


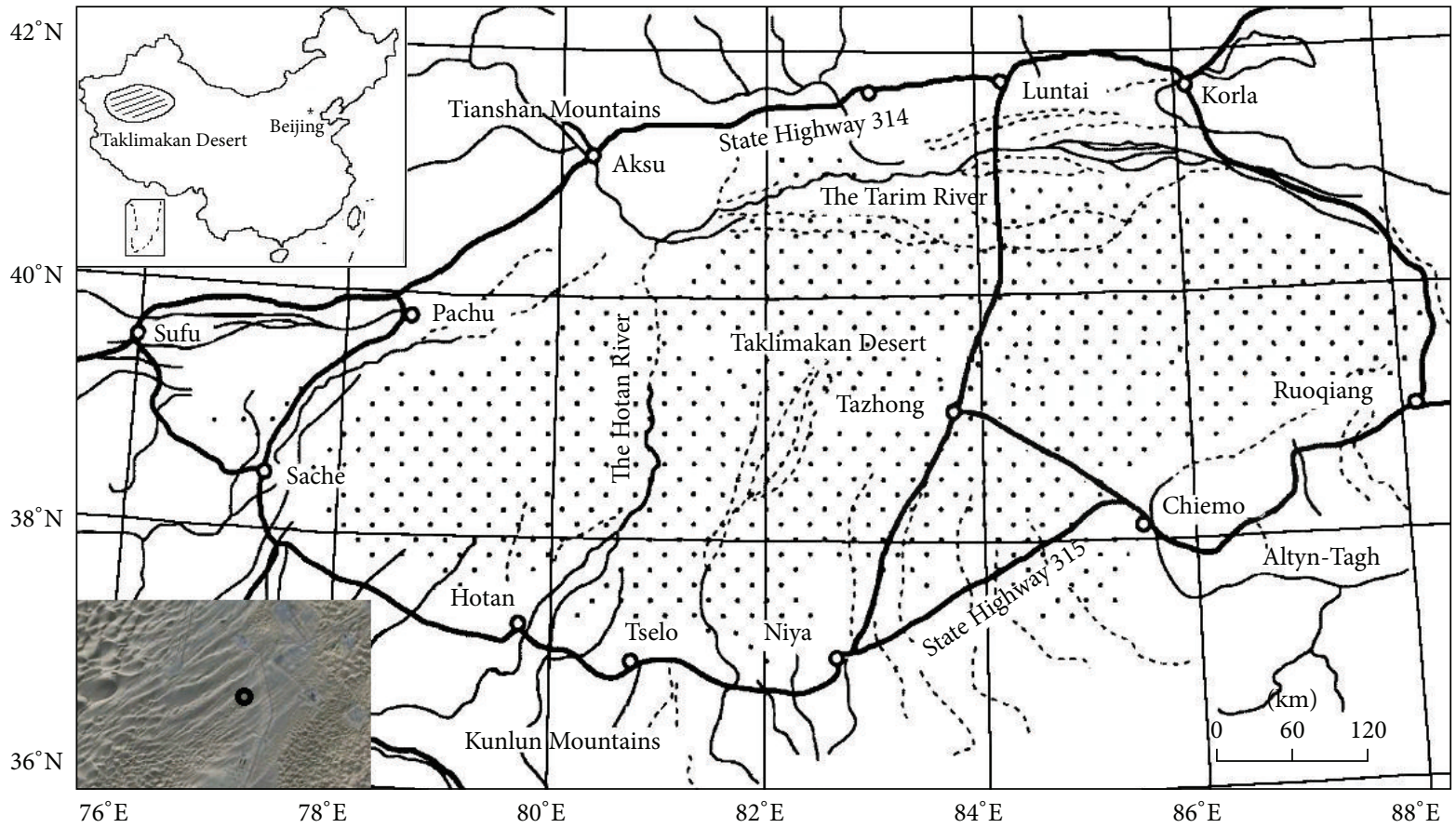

Figure 1: The Taklimakan Desert and the location of the Tazhong station within the Tarim depression. In the satellite photograph, the black circle is the location of the observational site, it shows that Tazhong area is mainly covered by dunes, and the site is located on a flat sandy land.

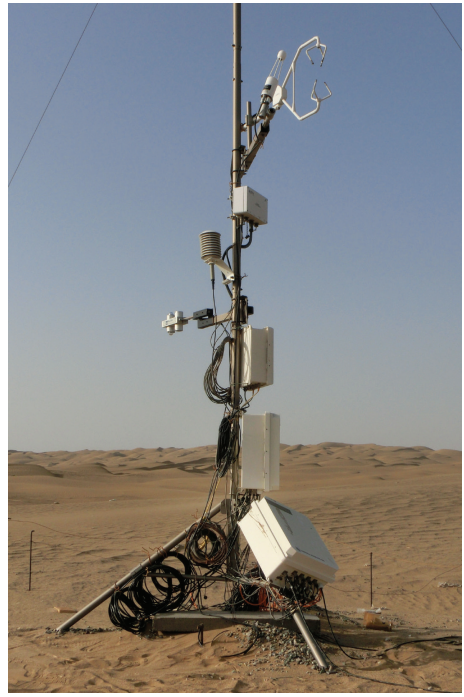

(a)

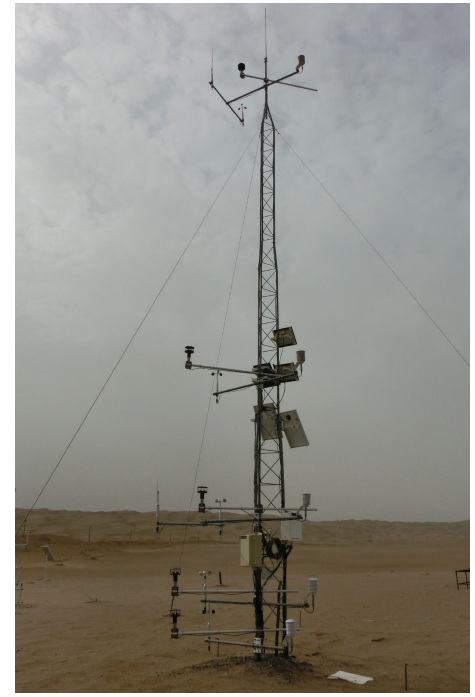

(b)

FiguRE 2: Eddy-covariance measurement system and radiation observation system on $3 \mathrm{~m}$ tower (a) as well as wind and temperature profiles measurement system on $10 \mathrm{~m}$ tower (b).

Kipp \& Zonen, The Netherlands), which measured solar and far infrared radiation, that is, the downward and upward shortwave and longwave radiation fluxes, respectively. These components were mounted at a height of $1.5 \mathrm{~m}$ on the same mast as the EC system, and the raw radiation data were stored at $1 \mathrm{~s}$ sampling intervals using a CR1000 data logger (also Campbell Scientific Inc., USA). The AWS is located
$30 \mathrm{~m}$ northeast of the EC system and collects data on wind speed/direction profile, air temperature/humidity profile, air pressure, and surface infrared temperature. All sensors were mounted on a $10 \mathrm{~m}$ tower in approximately twofold height interval, that is, $0.5,1,2,4$, and $10 \mathrm{~m}$ above the surface; they were erected at the top of solitary slim masts separated by a distance of approximately $1 \mathrm{~m}$ in order to reduce flow 
TABLE 2: Observational instrumentation ${ }^{\mathrm{a}}$.

\begin{tabular}{lcc}
\hline Observed items & Sensor & Height $(\mathrm{m})$ \\
\hline Turbulent fluxes, wind speed, air temperature & CSAT3, Campbell & 3 \\
Solar, longwave radiation & CNR-1, Kipp \& Zonen & 1.5 \\
Air temperature/humidity & HMP45D, Vaisala & $0.5,1,2,4,10$ \\
Wind speed & 010C, MetOne & $0.5,1,2,4,10$ \\
Wind direction & 020C, MetOne & 2,10 \\
Surface infrared temperature & IRR-P, Appage & 0 \\
Air pressure & PTB220B, Vaisala & 1 \\
\hline
\end{tabular}

${ }^{\mathrm{a}}$ Sensor includes sensor type and its manufacturer.

distortion and mutual interference induced by bolt supports and sensors. All of the AWS data were collected at $10 \mathrm{~s}$ intervals and the output data stored at 1 min intervals using the CR1000 data loggers. Detailed descriptions are provided in Table 2. All instrumentation used solar panels and battery power. Raw data were stored on CF cards and exported monthly to the laboratory for postprocessing. Data were processed rigorously with an averaging processing time of 30 min from January 1 to December 25, 2009.

2.3. Data Processing of the Turbulent Fluxes. Raw data were acquired at $10 \mathrm{~Hz}$ using the postprocessing software EdiRe (University of Edinburgh, http://www.geos.ed.ac.uk/abs/research/micromet/EdiRe), which includes spike removal, sonic virtual temperature correction, the performance of the planar fit coordinate rotation [19-22], and corrections for density fluctuation (WPL correction) [23]. In particular, the rotation correction aligns the coordinate system with the local mean streamline (streamline coordinates), effectively removing the advective flux from the total flux. Rotation into streamline coordinates insures that the calculated covariances are valid at the point of measurement. In addition to these processing steps, quality control of the half hourly flux data [24] was conducted based on the following criteria: (1) data from periods of sensor malfunction were rejected (e.g., when there was a faulty diagnostic signal), (2) data within $1 \mathrm{~h}$ before or after precipitation were rejected, (3) incomplete 30 min data were rejected when the missing data constituted more than $3 \%$ of the 30 min raw record, (4) data were rejected at night when the friction velocity was below $0.01 \mathrm{~m} \mathrm{~s}^{-1}$, and (5) data were rejected when wind speed was below $1.0 \mathrm{~m} \mathrm{~s}^{-1}$, and sensible heat flux was below $10 \mathrm{~W} \mathrm{~m}^{-2}$ or has the opposite sign as surface minus air temperature.

2.4. Data Processing of the Wind and Temperature Profiles. Observed data (1996-2013) at Tazhong station shows the annual sand and dust weather encompasses $260 \mathrm{~d}$. It leads to the cup anemometers that caused unexpected malfunction irregularly; therefore, the anemometers were periodically calibrated and maintained. The collected data were processed carefully, which obviously beyond the range of physical possibility were rejected. For the five levels (i.e., 0.5, 1.0, 2.0, 4.0 , and $10.0 \mathrm{~m}$ ), the wind directions were only observed simultaneously at level of 2.0 and $10.0 \mathrm{~m}$. Thus, the data of wind profile at level of 2.0 and $10.0 \mathrm{~m}$ were used in our study.
The data of temperature profile were also used at levels of 2.0 and $10.0 \mathrm{~m}$. For the final analysis, the quality control of the $30 \mathrm{~min}$ wind and temperature data is according to the following criteria: (1) data with more than $45^{\circ}$ of horizontal wind direction deviation from the coordinate system of sonic anemometer were rejected, (2) data were rejected when the variance of wind direction is larger than $15^{\circ}$, (3) data were rejected when the mean speed is below $1.0 \mathrm{~m} \mathrm{~s}^{-1}$, and (4) data were rejected when the temperature difference interval between 2.0 and $10.0 \mathrm{~m}$ is below $0.2 \mathrm{~K}$.

\section{Nondimensional Wind and Temperature Profile Functions}

3.1. The von Kármán Constant and Turbulent Prandtl Number. In the last few decades the von Kármán constant $(k)$ estimated from different data sources has shown large uncertainty, with its precise value supposed to vary from 0.32 to 0.65 in the atmospheric boundary layer [e.g., [25-31]]. The value of turbulent Prandtl number $\left(\operatorname{Pr}_{t}\right)$ under neutral stratifications is known to be close to unity, but there is no consensus on what the specific neutral value of $\operatorname{Pr}_{t}$ should be. Data from numerical simulations and experiments suggest $\operatorname{Pr}_{t}$ in the range $0.73-1.0$ with different authors $[1,32,33]$. Hence, following the approach of Andreas et al. [30] and Zhang et al. [28], we only use data in near-neutral conditions to determine $k$ and $\operatorname{Pr}_{t}$.

According to (1a), in near-neutral conditions, that is, for $z / L=0, \varphi_{m}(z / L)=1$, the nondimensional wind profile function can be written as

$$
\varphi_{m}\left(\frac{z}{L}\right)=\frac{k}{u_{*}} \frac{\Delta u}{\Delta \ln z}=1,
$$

and, consequently,

$$
k=\left[\frac{1}{u_{*}} \frac{\Delta u}{\Delta \ln z}\right]^{-1}, \quad \text { at } \frac{z}{L}=0 .
$$

Figure 3 shows the scatter plot of $k$ with respect to $|z / L|$. The values of $k$ are decreased with the increasingly atmospheric stability and are more gathered in stable stratification than in unstable stratification. The von Kármán constant is found to be 0.396 with the standard deviation of 0.10 by averaging values in the range of $|z / L| \leq 0.1$.

The value of $\operatorname{Pr}_{t}$ was studied in a similar manner to $k$. According to (1a) and (1c), in near-neutral conditions, 


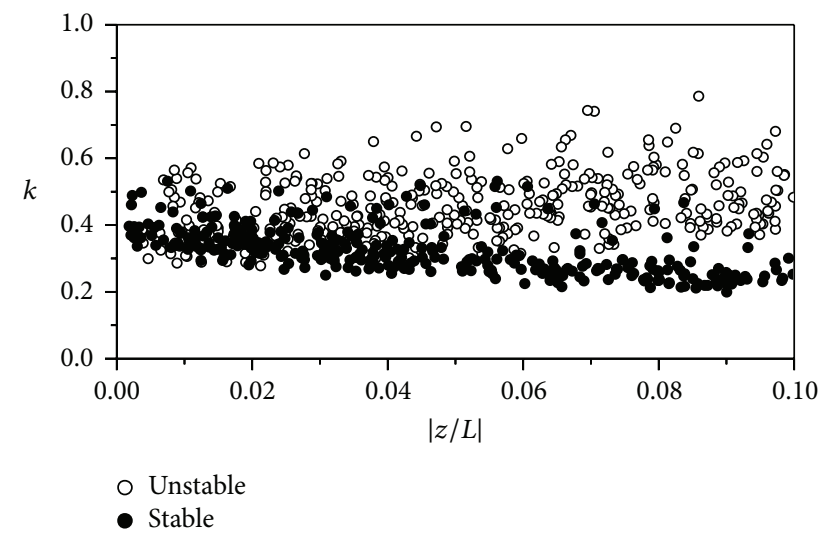

Figure 3: The scatter plot of the von Kármán constant $(k)$ with respect to $|z / L| \leq 0.1$.

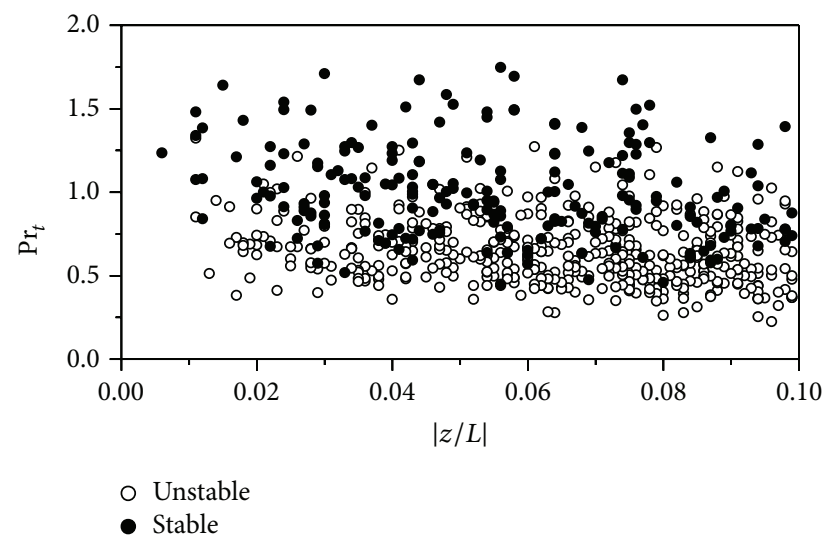

Figure 4: The scatter plot of the turbulent Prandtl number $\left(\operatorname{Pr}_{t}\right)$ against $|z / L| \leq 0.1$ with $k=0.396$.

$\varphi_{m}(z / L)=\varphi_{h}(z / L)=1$. Thus, the turbulent Prandtl number $P r_{t}=K_{m} / K_{h} \equiv \varphi_{m} / \varphi_{h}$ is given by

$$
\operatorname{Pr}_{t}=\frac{\left[\left(k / \theta_{*}\right)(\Delta \theta / \Delta \ln z)\right]}{\left[\left(k / u_{*}\right)(\Delta u / \Delta \ln z)\right]}=\frac{\Delta \theta}{\Delta u} \frac{u_{*}}{\theta_{*}}, \quad \text { at } \frac{z}{L}=0 .
$$

Figure 4 shows the scatter plot of $\operatorname{Pr}_{t}$ against $z / L$ in a narrow stability range $(|z / L| \leq 0.1)$ with $k=0.396$. Obviously, the scatter is large in unstable stratification. The values in unstable conditions with mean value of 0.64 are less than that in stable conditions with mean value of 1.0. Nevertheless, the averaged turbulent Prandtl number is found to be 0.75 with a standard deviation of 0.28 in stability range of $|z / L| \leq 0.1$. There are few data points in stable conditions because all data with sensible heat flux below $10 \mathrm{~W} \mathrm{~m}^{2}$ or $\Delta \theta \leq 0.2 \mathrm{~K}$ were rejected from the analysis.

3.2. The Nondimensional Wind and Temperature Profile Functions. The nondimensional wind profile function $\left(\varphi_{m}\right)$ determined from (2a) and $\beta_{m}$ and $\gamma_{m}$ are given by

$$
\beta_{m}=\frac{\left[\left(k / u_{*}\right)(\Delta u / \Delta \ln z)-1\right]}{(z / L)} \quad \frac{z}{L}>0,
$$

TABLE 3: Coefficients of nondimensional profile functions ${ }^{\mathrm{a}}$.

\begin{tabular}{lccc}
\hline Coefficient & Stability range & Mean value & Standard deviation \\
\hline$\beta_{m}$ & $0 \leq z / L \leq 2$ & 5.4 & 2.3 \\
$\gamma_{m}$ & $-2 \leq z / L \leq 0$ & 13.0 & 6.4 \\
$\beta_{h}$ & $0 \leq z / L \leq 2$ & 6.1 & 2.3 \\
$\frac{\gamma_{h}}{{ }^{\mathrm{a}} \text { Mean value }=(1 / n) \sum_{i=1}^{n} x_{i} . \text { Standard deviation }=\sqrt{(1 / n) \sum_{i=1}^{n}\left(x_{i}-\bar{x}\right)^{2}} .}$ \\
\\
$\gamma_{m}=\frac{\left[1-\left(\left(k / u_{*}\right)(\Delta u / \Delta \ln z)\right)^{-4}\right]}{(z / L)}$ & $\frac{z}{L} \leq 0$.
\end{tabular}

Similarly, the nondimensional temperature profile function $\left(\varphi_{h}\right)$ determined from (2b) and $\beta_{h}$ and $\gamma_{h}$ are given by

$$
\begin{aligned}
& \beta_{h}=\frac{\left[\left(k / \theta_{*}\right)(\Delta \theta / \Delta \ln z) / \mathrm{Pr}_{t}-1\right]}{(z / L)} \quad \frac{z}{L}>0, \\
& \gamma_{h}=\frac{\left[1-\left(\left(k / \theta_{*}\right)(\Delta \theta / \Delta \ln z) / \operatorname{Pr}_{t}\right)^{-2}\right]}{(z / L)} \quad \frac{z}{L} \leq 0 .
\end{aligned}
$$

Therefore, $\beta_{m}, \gamma_{m}, \beta_{h}$, and $\gamma_{h}$ can be estimated with $k=$ 0.396 and $\operatorname{Pr}_{t}=0.75$. The values of coefficients and standard deviations are shown in Table 3. Thus, the nondimensional wind and temperature profile functions at Tazhong station are determined

$$
\begin{aligned}
& \varphi_{m}\left(\frac{z}{L}\right)= \begin{cases}1+\frac{5.4 z}{L} & \frac{z}{L}>0 \\
\left(1-\frac{13 z}{L}\right)^{-1 / 4} & \frac{z}{L} \leq 0,\end{cases} \\
& \varphi_{h}\left(\frac{z}{L}\right)= \begin{cases}0.75\left(1+\frac{6.1 z}{L}\right) & \frac{z}{L}>0 \\
0.75\left(1-\frac{22 z}{L}\right)^{-1 / 2} & \frac{z}{L} \leq 0 .\end{cases}
\end{aligned}
$$

Figure 5(a) compares measured $\varphi_{m}$ with the ones calculated from (8a). The calculated values correlate well with the observed data, with $R^{2}$ value of 0.66 for stable stratification and 0.11 for unstable stratification. Similarly, Figure 5(b) compares the measured $\varphi_{h}$ with the values calculated from (8b). The calculated values correlate also well with the observed data, with $R^{2}$ value of 0.20 for stable stratification and 0.67 for unstable stratification.

3.3. Comparison of Typical Nondimensional Profile Functions. Although the nondimensional wind and temperature profile functions, at Tazhong station, have similar trend to other six typical ones in Table 1, its differences to other six typical profile functions were unknown. Thus, Table 4 shows the RMSE (Root Mean Squared Error) and percent difference (not shown) of profile functions using our revised formula compared to other six typical ones against $z / L$.

For unstable stratification, $\operatorname{six} z / L$ values (i.e., $-2.0,-1.0$, $-0.5,-0.25,-0.1$, and -0.02 ) are used to represent the full 


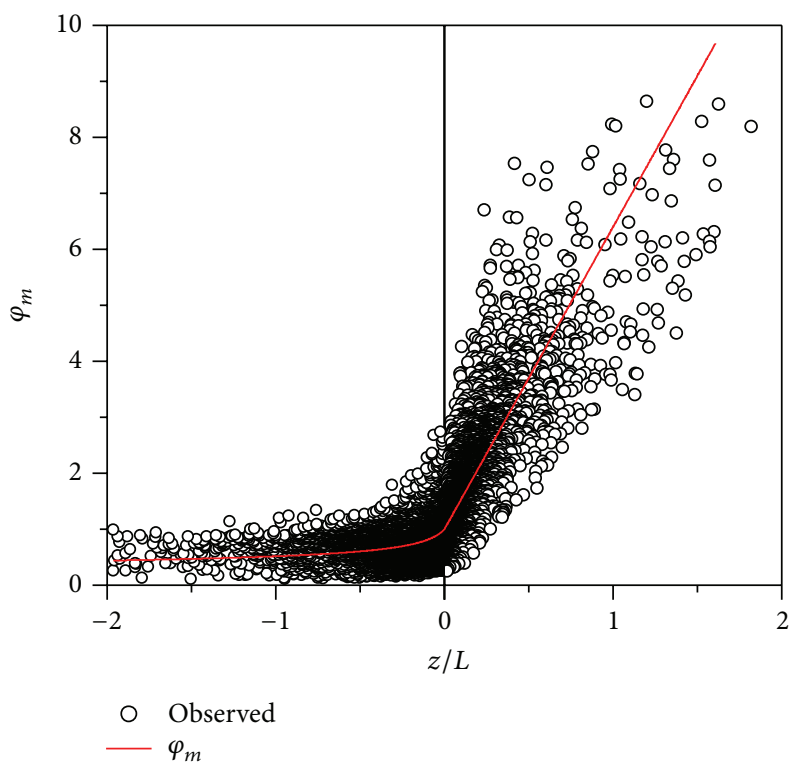

(a)

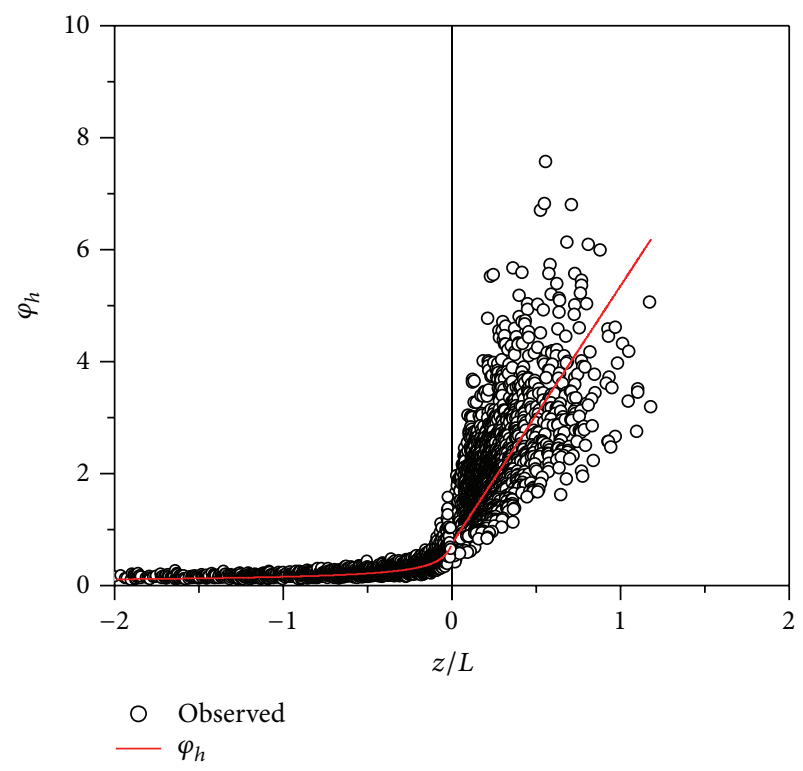

(b)

FIGURE 5: (a) Observed and calculated nondimensional wind profile function $\varphi_{m}$ against $z / L$. The solid lines are obtained from (8a). (b) As (a), but for $\varphi_{h}$, the solid lines are obtained from (8b).

TABLE 4: The RMSE using our revised $\varphi_{m}$ and $\varphi_{h}$ compared to six typical ones ${ }^{\mathrm{a}}$.

\begin{tabular}{lcccccc}
\hline Profile function & Stability range & B71 & D74 & W80 & Z93 & H96 \\
\hline$\varphi_{m}$ & $-2 \leq z / L \leq-0.02$ & 0.016 & 0.023 & 0.059 & 0.086 & 0.043 \\
$\varphi_{m}$ & $0.02 \leq z / L \leq 0.5$ & 0.199 & 0.114 & 0.426 & 0.085 & $\mathbf{0 . 0 2 8}$ \\
$\varphi_{m}$ & $-2 \leq z / L \leq 0.5$ & 0.121 & 0.071 & 0.261 & 0.082 & 0.013 \\
$\varphi_{h}$ & $-2 \leq z / L \leq-0.02$ & 0.099 & 0.167 & 0.194 & 0.138 & 0.182 \\
$\varphi_{h}$ & $0.02 \leq z / L \leq 0.5$ & $\mathbf{0 . 0 9 9}$ & 0.244 & 1.379 & 0.266 & 0.887 \\
$\varphi_{h}$ & $-2 \leq z / L \leq 0.5$ & $\mathbf{0 . 0 9 4}$ & 0.206 & 0.847 & 0.204 & 0.555 \\
\hline
\end{tabular}

${ }^{\mathrm{a}} \mathrm{RMSE}=\sqrt{(1 / n) \sum_{i=1}^{n}\left(x_{i}-y_{i}\right)^{2}}$, where $x_{i}$ stand for profile functions at Tazhong station and $y_{i}$ stand for six typical ones in Table 1.

range of $-2 \leq z / L \leq-0.02$. For stable stratification, four $z / L$ values (i.e., $0.02,0.1,0.25$, and 0.5 ) are used to represent the full range of $0.02 \leq z / L \leq 0.5$. For $z / L>0.5$ most studies show increasing scatter for both $\varphi_{m}$ and $\varphi_{h}$ and the general trend becomes independent of $z / L$ [17]. Therefore, results for $z / L>0.5$ are not taken into account.

As shown in Table 4, the nondimensional wind profile function $\varphi_{m}$ at Tazhong station is close to Z03 in unstable conditions but close to H96 in stable conditions. Similarly, $\varphi_{h}$ is also close to Z03 in unstable conditions but similar to B71 in stable conditions. However, for entire stability range $-2 \leq z / L \leq 0.5, \varphi_{m}$ is close to H96 within $9.6 \%$ difference and $\varphi_{h}$ is close to $\mathrm{B} 71$ within $34.1 \%$ difference.

\section{Conclusions}

In this study, we have used the observed turbulent fluxes, wind, and temperature profiles over the hinterland of the Taklimakan Desert at Tazhong station from January to December 2009 to examine all empirical parameters involved in the profile functions based on MOS.
We have found that the von Kármán constant $(k)$ is 0.396 , in agreement with previous studies. The turbulent Prandtl number $\left(\mathrm{Pr}_{t}\right)$ is 0.75 in near-neutral stratification. Based on these $k$ and $\mathrm{Pr}_{t}$, the nondimensional wind profile function is $\varphi_{m}=(1-13 z / L)^{-1 / 4}$ for $z / L \leq 0, \varphi_{m}=1+5.4 z / L$ for $z / L>0$. The nondimensional temperature profile function is $\varphi_{h}=0.75(1-22 z / L)^{-1 / 2}$ for $z / L \leq 0, \varphi_{h}=0.75(1+6.1 z / L)$ for $z / L>0$.

The presently derived nondimensional profile functions are similar to those previously reported. Our study confirms that the nondimensional functional forms for wind and temperature profile functions still hold in the Taklimakan Desert. However, the parameters used in the profile functions need to be revised to be applicable to the Taklimakan Desert. Therefore, it is inapplicable to directly apply the universal profile functions to estimate surface momentum and heat flux in desert regions.

\section{Conflict of Interests}

The authors declare that there is no conflict of interests regarding the publication of this paper. 


\section{Acknowledgments}

The research was partially supported by $R$ \& D Special Fund for Nonprofit Industry of China (Meteorology, GYHY201306066) and National Natural Science Foundation of China (41265002, 41305107).

\section{References}

[1] T. Foken, "50 years of the Monin-Obukhov similarity theory," Boundary-Layer Meteorology, vol. 119, no. 3, pp. 431-447, 2006.

[2] J. A. Businger, J. C. Wyngaard, Y. Izumi, and E. F. Bradley, "Fluxprofile relationships in the atmospheric surface layer," Journal of the Atmospheric Sciences, vol. 28, no. 2, pp. 181-189, 1971.

[3] A. S. Monin and A. M. Obukhov, "Basic laws of turbulent mixing in the atmosphere near the ground," Translated by Geophysical Institute of Akademii Nauk SSSR, vol. 24, no. 151, pp. 163-187, 1954.

[4] W. Brutsaert and W. P. Kustas, "Evaporation and humidity profiles for neutral conditions over rugged hilly terrain," Journal of Climate \& Applied Meteorology, vol. 24, no. 9, pp. 915-923, 1985.

[5] W. Brutsaert and W. P. Kustas, "Surface water vapor and momentum fluxes under unstable conditions from a ruggedcomplex area.", Journal of the Atmospheric Sciences, vol. 44, no. 2, pp. 421-431, 1987.

[6] M. Sugita and W. Brutsaert, "Wind velocity measurements in the neutral boundary layer above hilly prairie," Journal of Geophysical Research: Atmospheres, vol. 95, no. 6, pp. 7617-7624, 1990.

[7] M. B. Parlange and W. Brutsaert, "Regional shear stress of broken forest from radiosonde wind profiles in the unstable surface layer," Boundary-Layer Meteorology, vol. 64, no. 4, pp. 355-368, 1993.

[8] N. L. Dias and W. Brutsaert, "Similarity of scalars under stable conditions," Boundary-Layer Meteorology, vol. 80, no. 4, pp. 355-373, 1996.

[9] Y. Cheng and W. Brutsaert, "Flux-profile relationships for wind speed and temperature in the stable atmospheric boundary layer," Boundary-Layer Meteorology, vol. 114, no. 3, pp. 519-538, 2005.

[10] U. Högström, "Non-dimensional wind and temperature profiles in the atmospheric surface layer: a re-evaluation," BoundaryLayer Meteorology, vol. 42, no. 1, pp. 55-78, 1988.

[11] A. J. Dyer and B. B. Hicks, "Flux-gradient relationships in the constant flux layer," Quarterly Journal of the Royal Meteorological Society, vol. 96, no. 410, pp. 715-721, 1970.

[12] E. K. Webb, "Profile relationships: the log-linear range, and extension to strong stability," Quarterly Journal of the Royal Meteorological Society, vol. 96, no. 407, pp. 67-90, 1970.

[13] D. M. Carl, T. C. Tarbell, and H. A. Panofsky, "Profiles of wind and temperature from towers over homogeneous terrain," Journal of the Atmospheric Sciences, vol. 30, no. 5, pp. 788-794, 1973.

[14] A. J. Dyer, "A review of flux-profile relationships," BoundaryLayer Meteorology, vol. 7, no. 3, pp. 363-372, 1974.

[15] J. Wieringa, "A revaluation of the Kansas mast influence on measurements of stress and cup anemometer overspeeding," Boundary-Layer Meteorology, vol. 18, no. 4, pp. 411-430, 1980.
[16] K. Kai, "Statistical characteristics of turbulence and the budget of turbulent energy in the surface boundary layer," Environmental Research Center Paper 1, University of Tsukuba, Tsukuba, Japan, 1982.

[17] U. Högström, "Review of some basic characteristics of the atmospheric surface layer," Boundary-Layer Meteorology, vol. 78, no. 3-4, pp. 215-246, 1996.

[18] Q. Zhang, R. Huang, and H. Tian, "A parameterization scheme of surface turbulent momentum and sensible heat over the Gobi underlying surface," Advances in Atmospheric Sciences, vol. 20, no. 1, pp. 111-118, 2003.

[19] R. T. McMillen, "An eddy correlation technique with extended applicability to non-simple terrain," Boundary-Layer Meteorology, vol. 43, no. 3, pp. 231-245, 1988.

[20] J. C. Kaimal and J. J. Finnigan, Atmospheric Boundary Layer Flows: Their Structure and Measurement, Oxford University Press, Oxford, UK, 1994.

[21] X. Lee, "On micrometeorological observations of surface-air exchange over tall vegetation," Agricultural and Forest Meteorology, vol. 91, no. 1-2, pp. 39-49, 1998.

[22] J. M. Wilczak, S. P. Oncley, and S. A. Stage, "Sonic anemometer tilt correction algorithms," Boundary-Layer Meteorology, vol. 99, no. 1, pp. 127-150, 2001.

[23] E. K. Webb, G. I. Pearman, and R. Leuning, "Correction of flux measurements for density effects due to heat and water vapour transfer," Quarterly Journal of the Royal Meteorological Society, vol. 106, no. 447, pp. 85-100, 1980.

[24] T. Foken, M. Göckede, M. Mauder, L. Mahrt, B. Amiro, and W. Munger, "Post-field data quality control," in Handbook of Micrometeorology: A Guide for Surface Flux Measurement and Analysis, X. Lee, W. Massman, and B. Law, Eds., pp. 181-208, Kluwer Academic Publishers, Dordrecht, The Netherlands, 2004.

[25] H. Tennekes, "The logarithmic wind profile," Journal of the Atmospheric Sciences, vol. 30, no. 2, pp. 234-238, 1973.

[26] J. Kondo and T. Sato, "The determination of the von Kármán constant," Journal of the Meteorological Society of Japan, vol. 60, no. 1, pp. 461-471, 1982.

[27] H. A. Panofsky and J. A. Dutton, Atmospheric Turbulence: Models and Methods for Engineering Applications, Wiley, New York, NY, USA, 1984.

[28] S. F. Zhang, S. P. Oncley, and J. A. Businger, "A critical evaluation of the von Kármán constant for a new atmospheric surface layer experiment," in Proceedings of 8th Symposium on Atmospheric Turbulence and Diffusion, pp. 148-150, American Meteorological Society, San Diego, Calif, USA, 1988.

[29] S. P. Oncley, C. A. Friehe, J. C. Larue, J. A. Businger, E. C. Itsweire, and S. S. Chang, "Surface-layer fluxes, profiles, and turbulence measurements over uniform terrain under near-neutral conditions," Journal of the Atmospheric Sciences, vol. 53, no. 7, pp. 1029-1044, 1996.

[30] E. L. Andreas, K. J. Claffy, R. E. Jordan et al., "Evaluations of the von Kármán constant in the atmospheric surface layer," Journal of Fluid Mechanics, vol. 559, pp. 117-149, 2006.

[31] Y. Zhang, J. Ma, and Z. Cao, "The Von Kármán constant retrieved from CASES-97 dataset using a variational method," Atmospheric Chemistry and Physics, vol. 8, no. 23, pp. 70457053, 2008.

[32] M. M. Gibson and B. E. Launder, "Ground effects on pressure fluctuations in the atmospheric boundary layer," Journal of Fluid Mechanics, vol. 86, no. 3, pp. 491-511, 1978. 
[33] A. M. Yaglom, "Similarity laws for constant-pressure and pressure-gradient turbulent wall flows," Annual Review of Fluid Mechanics, vol. 11, no. 1, pp. 505-540, 1979.

[34] H. S. Zhang, J. Y. Chen, A. C. Zhang, J. M. Wang, and Y. Mitsuta, "An experiment and the results on flux-gradient relationships in the atmospheric surface over Gobi desert surface," in Proceedings of International Symposium on HEIFE, pp. 349-362, Kyoto, Japan, 1993. 

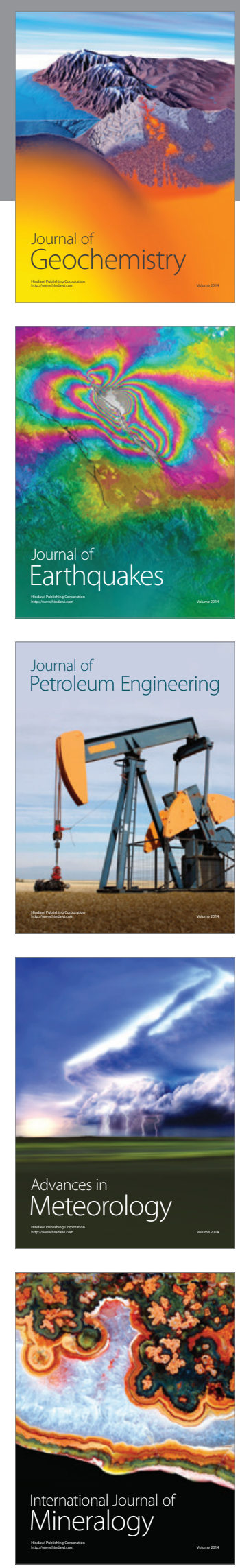
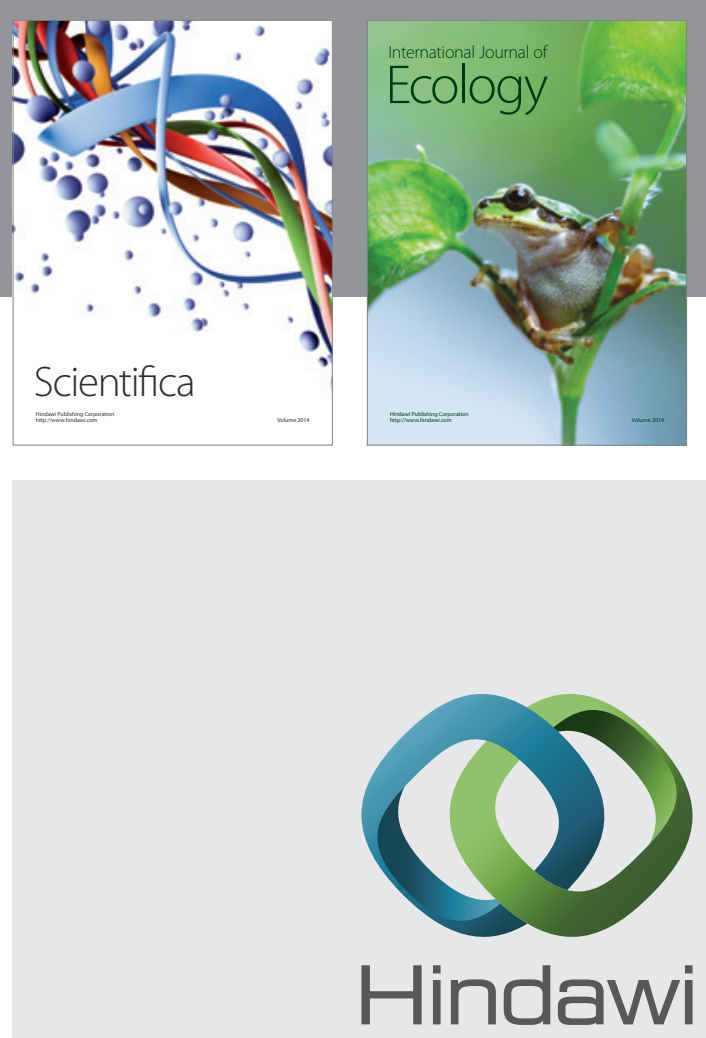

Submit your manuscripts at

http://www.hindawi.com
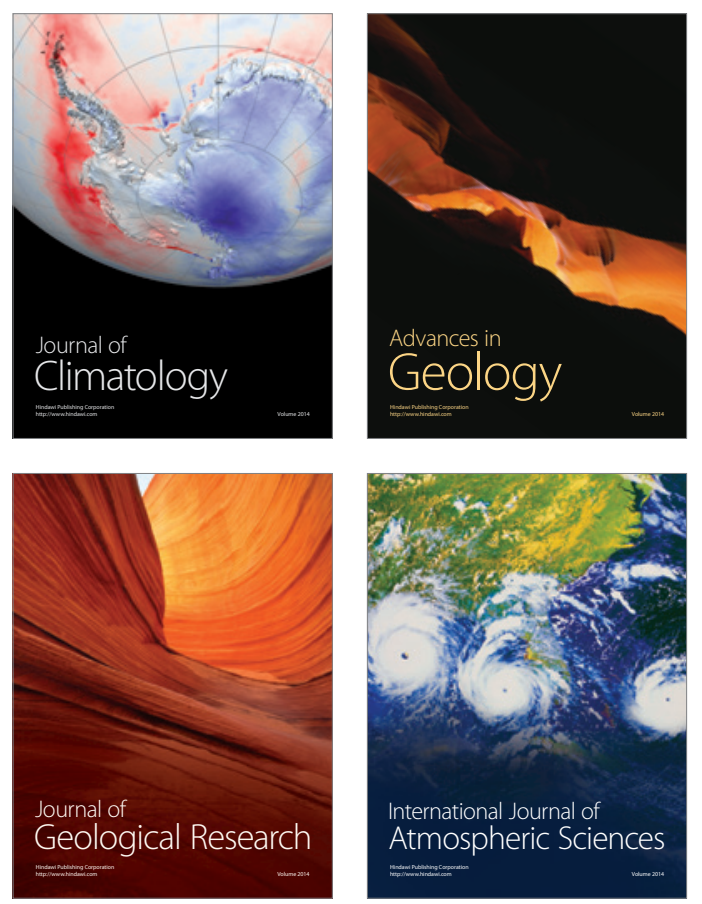

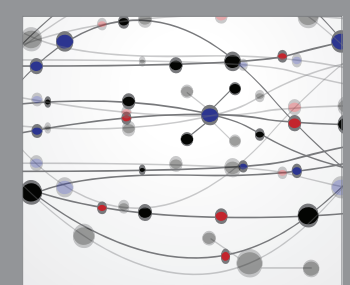

The Scientific

\section{World Journal}
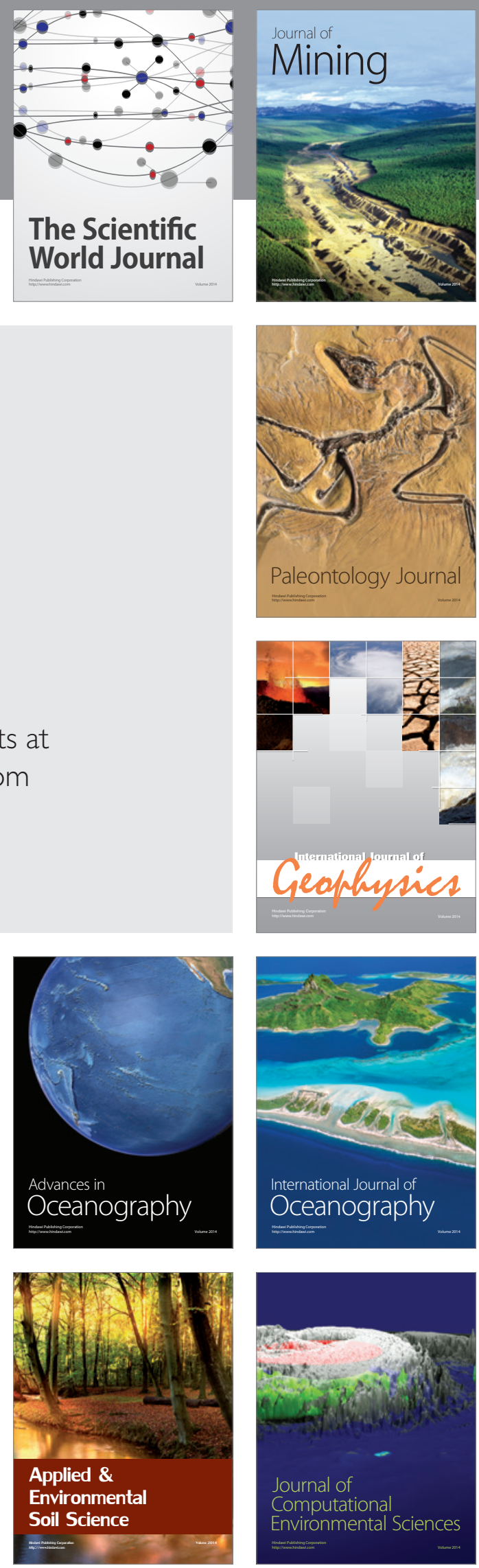